\title{
Status of Vaccination Against Hepatitis B Among Dental Assistants of Multan
}

\author{
Mohsin Javaid ${ }^{1}$ \\ Muhammad Jamil ${ }^{2}$ \\ Mustafa Sajid $^{3}$ \\ BDS \\ BDS, FDS RCS \\ BDS, FCPS
}

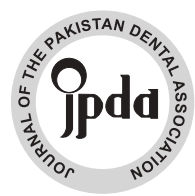

OBJECTIVE: Direct contact of dental health care workers with patients make them prone to get infection with hepatitis B and other communicable disease. The Objective of this study was to find out the status of vaccination against of Hepatitis B virus among dental assistants of Multan.

METHODOLOGY: This questionnaire-based cross-sectional study was conducted in Multan Medical \& Dental College, from Sept 2018-Nov 2018. Ninety-five dental assistants filled a questionnaire designed and tested for this study. The ethical approval (MDC-0409) was taken from the Dental hospital, informed consent was obtained from the participants in the study. RESULTS: Out of Ninety five participants, $68.42 \%$ participants were males and $31.58 \%$ were females. $89.48 \%$ participants were in favor of vaccinating against hepatitis B for dental assistant, while $44.21 \%$ participants were already vaccinated. Lack of motivation was the main reason for not receiving vaccination.

CONCLUSION: Self-reported rate of hepatitis B vaccination among Dental Assistants of Multan was low. Lack of motivation was the main impediment.

KEY WORDS: Hepatitis B vaccine, Dental Assistants, Health care workers, Dental health professionals.

HOW TO CITE: Javaid M, Jamil M, Sajid M. Status of vaccination against hepatitis B among dental assistants of multan. J Pak Dent Assoc 2020;29(1):42-45.

DOI: https://doi.org/10.25301/JPDA.291.42

Received: 21 December 2018, Accepted: 14 October 2019

\section{INTRODUCTION}

$\mathrm{D}$ ental care professionals including doctors and dental assistant are at high risk of getting infected with Hep B and HIV. As Dental healthcare workers are in direct contact with the infected patients, they are athigh risk of getting infected with hepatitis B and other blood endured disorders. ${ }^{1}$ Hepatitis B is a common disease which can be fatal. ${ }^{2}$ Dentist are profoundly at risk of getting infected from patient's saliva and blood. ${ }^{3}$ Stick Injuries with needle or other sharp instruments used during medical procedures and blood transfusion have the risk to transfer hepatitis B among the medicinal services specialists, Thus it is important to prepare for safety measures to avoid cross infection with Hepatitis B. ${ }^{4}$ Dental assistants work closely with patients, under the guidance of a dental surgeon. They

1. Demonstrator, Department of Community Dentistry, Multan Medical and Dental College Multan.

2. Associate Professor, Department of Operative Dentistry, Multan Medical and Dental College Multan.

3. Assistant Professor, Department of Operative Dentistry, Multan Medical and Dental College Multan.

Corresponding author: "Dr. Mustafa Sajid" < mustafa_sajid_@hotmail.com > are at risk during handling of instruments especially sharp instruments with naked hands or without care. ${ }^{5}$ Practicing strict cross infection controlregulation activities are vital to guarantee the wellbeing and insurance of human service experts and other coordinating staff who might be indirectly associated with the dental treatment procedure. ${ }^{7}$ It is an ethical duty of an employee to protect the patient and health care assistant from cross infection contamination. ${ }^{6}$

Immunization against Hepatitis B should be mandatory for every health care worker. Prophylactic estimates like inoculation, the risk of infection increasesfrom 6\%-30\% in non-vaccinated individuals, and decreases the risk of cross infection from $90 \%-95 \%{ }^{8}$ According to the survey of World Health Organization, Eighteen to Thirty nine percent therapeutic, oral health care workers have inoculation in developing nations e.g Argentina, Algeria. ${ }^{9}$ While in developed nations level of inoculated medicinal services specialists is raised up to Ninety-five percent. ${ }^{10,11,12}$ Cross infection of hepatitis B can be decreased if healthcare workers properly dispose-off the sharps and do proper sterilization of the instruments. ${ }^{14}$

The Objective of this study was to find out the status of vaccinationagainst Hepatitis B virus among dental 
assistants of Multan. As the literature demonstrates that most of the studies regarding cross infection and hepatitis $B$ vaccination status had been done on doctors and students but our study focused on the Dental assistants to overcome the knowledge gap. Dental assistants also have less awareness regarding cross infection and vaccination status against hepatitis $B$ virus.

\section{METHODOLOGY}

This questionnaire-based cross-sectional study was conducted in Multan Medical and Dental College from September 2018 to November 2018. Dental Assistants working for last one year were included in this study. Assistants who had less than one-year experience were excluded from the study because the tenure of complete vaccination process is at-least 6 months. 95 participants completed questionnaire including the vaccination status and if not vaccinated then the reasons for non-vaccination. Validity was confirmed by the pilot testing in hospital.Sample size was calculated by using Open-Epi online calculator with the level of significance of $5 \%$ and confidence interval of $95 \%$, the final sample size was calculated as 95. Simple random sampling was used in order to get desired sample size. Estimated number of dental assistants in Multan were approximately 250, adjustment was done by Cochrane correction formula. A pretest was conducted on a random sample of 10 dental assistants $(\mathrm{n}=10)$ that were not included in this study. Ethical approval (MDC-0409) was taken from Multan dental hospital and after taking the informed consent from the participants.

\section{RESULTS}

Out of 95 participants, 65 were males and 30 were females. $44.2 \%$ dental assistants were vaccinated but $55.8 \%$ were not vaccinated and had different reasons for being notvaccinated, $40 \%$ participants did not get vaccinated due to lack of motivation. (Table 1)

From a total of $55.8 \%$ non-vaccinated dental assistants, $10.6 \%$ were non-vaccinated due to lack of awareness.Dental assistants who remained nonvaccinated due to lack of time were $8.42 \% .{ }^{4}$ Among $13.68 \%$ participants reported that the distant vaccination center was the main reason for their non-vaccination. The participants who did not get vaccine due to non-motivation were $40 \%$ and among $23.1 \%$ dental assistants reported phobia to the injection while $4.2 \%$ participantsreported that they could not afford the said vaccination as it is very expensive.
Table 1: Percentage of Vaccinated Dental Assistants

\begin{tabular}{|l|l|}
\hline REASONS & Frequency \& Percentage (\%) \\
\hline UNAWARENESS & $6(10.6 \%)$ \\
\hline LACK OF TIME & $4(8.42 \%)$ \\
\hline DISTANT VACCINATION CENTRE & $7(13.68 \%)$ \\
\hline EXPENSIVE MEDICINE & $3(4.2 \%)$ \\
\hline NON-MOTIVATED & $21(40 \%)$ \\
\hline INJECTION PHOBIC & $12(23.1 \%)$ \\
\hline TOTAL NON-VACCINATED & $53(55.8 \%)$ \\
\hline VACCINATED & $42(44.2 \%)$ \\
\hline TOTAL & 95 \\
\hline
\end{tabular}

\section{DISCUSSION}

According to CDC rules overall wellbeing measures are set of exercises which are fundamental to avoid hepatitis B infection. Vaccination against hepatitis B virus is extremely essential to control cross infection of hepatitis B in dental assistants and patients as well. ${ }^{15}$

Results of this research shows that forty-four percent dental assistant were vaccinated against hepatitis B virus which is contrary to another study in which $88 \%$ healthcare workers got vaccination in Saudi Arabia. ${ }^{16}$ Health department of Saudi Arabia has made sure that each health care worker must receive vaccination before getting job.

There are many reasons for not receiving vaccination like unawareness, injection phobic, expensive medicine, non-motivated participants, distant vaccination center and lack of time. ${ }^{17}$

Another study on vaccination status conducted in Bangladesh stated that $47 \%$ assistants were vaccinated in 2015 in tertiary care hospitals. These results are very much similar tothis study in which forty four percent assistants are vaccinated. ${ }^{18}$

In 2008 a study conducted in Japan concluded that dental health care workers are more prone to be infected with hepatitis B virus than general population. That is why dental health care workers must have vaccination against hepatitis B virus. ${ }^{19}$ Results of this study are similar to the study conducted in Japan. Percentage of vaccinated dental workers was $48 \%$ while in this study vaccination rate is $44 \% .{ }^{19}$ It is extremely important to note that vaccination status of dental assistants around the world is between $33 \%$ to $97 \%$. The 
percentage of vaccinated people were more secured to hepatitis B virus than non-vaccinated which shows that hepatitis B virus vaccination is an important measure for security against disease. ${ }^{19} \mathrm{~A}$ research was conducted in Nigeria which stated that $16 \%$ participants failed to receive complete vaccination due to lack of knowledge while in this study $10.6 \%$ participants failed to get vaccination due to unawareness. In present study $44.2 \%$ received vaccination against Hep B where as another study shows contradicting results $60.02 \% .^{20}$ According to a study conducted in Oyebimpe. 5.3\% participants did not received any vaccination because of unavailability but in this study percentage climbs up to $11.2 \%$. In the study of Oyebimpe busy schedule has been reported to be a major cause $57.9 \%$ healthcare workers did not get vaccination owing to their busy schedule. While in this present study almost $8.42 \%$ participants didn't received any vaccine against Hepatitis B due too busy schedule. Distant vaccination center was second most common reason for non-vaccination after busy schedule. In the study of Oyebimpe $21.1 \%$ participants did not receive vaccination due to distant vaccination center but in our study it was $3.68 \%$. Unawareness is also the cause which keeps the participants away from vaccination process. $15.3 \%$ healthcare workers in the study of Oyebimpe reported that they were not aware of a vaccination process while in this study this percentage was $10.6 \% .^{21}$

Another study was performed in Syrian private Medical University which revealed that $43.75 \%$ participants receive vaccination and the results corroborate to the result of present study. In this study most of the participants failed to get vaccine due to lack of motivation which is similar to Syrian study where lack of motivation was the major cause of failure. Needle phobia is major cause of non-vaccinated participants. In this study $23.1 \%$ participants reported phobia to injection but in Syrian investigation the percentage was reduced to Eight percent. ${ }^{22}$

In 2007, Seventy-five percent health care workers were vaccinated in United States ${ }^{23}$ while in this study only $44.2 \%$ participants received vaccination. Results of this study are slightly better than another study from Lahore where vaccination rate was $42.20 \%$ among the health care providers. ${ }^{24}$

In Kuwait eighty-four percentdoctors and paramedical staff got vaccination against the hepatitis B virus. While in our study vaccination rate was very low ascompared to that of Kuwait. ${ }^{25}$

\section{CONCLUSION}

The self- reported rate of hepatitis B vaccination among Dental Assistants of Multan was low. Lack of motivation was the main impediment. Dental institutes should take responsibility to educate their health care workers regarding precautions and vaccination against hepatitis B virus.

\section{CONFLICT OF INTEREST}

None declared

\section{REFERENCES}

1. Laheij AMGA, Kistler JO, Belibasakis GN, Välimaa H, de Soet JJ. Healthcare-associated viral and bacterial infections in dentistry. J Oral Microbiol . $2012 ; 4: 1-10$

https://doi.org/10.3402/jom.v4i0.17659

2. Patil S, Rao RS, Agarwal A. Awareness and risk perception of hepatitis B infection among auxiliary healthcare workers. J IntSocPrev Community Dent. 2013;3:67-71

https://doi.org/10.4103/2231-0762.122434

3. What is dental PPE and why is it so important?|My Dental Uniform. August 2017.Cited from: http://www.mydentaluniform.co.uk

4. Setia S, Gambhir R, Jindal G, Setia S. Attitudes and awareness regarding hepatitis $\mathrm{B}$ and hepatitis $\mathrm{C}$ amongst health-care workers of a tertiary hospital in India. Ann Med Health Sci Res. 2013;3:551-58. https://doi.org/10.4103/2141-9248.122105

5. A Dental Assistant's Guide to Infection Control. August 252015. Cited from: https://www.canadianacademyofdentalhygiene.ca

6. Mousa, AA, Mahmoud NM, El-Din, AZT. Knowledge, attitudes of dental patients towards cross-infection control measures in dental practice. Eastern Medit Health J,1997; 3: 263-73

7. Infection control in dentistry has never been more essential - Dental News Pakistan [cited 2017 Nov 25]

8. Viral hepatitis B. Fact sheet [online] October 1,2004. (last accessed on August 12, 2015)

9. CDC. Updated U.S: public health service guidelines for the man $\neg$ agement of occupational exposures to HBV, HCV, and HIV and recommendations for post exposure prophylaxis. MMWR 2001, 50 (No. RR-11):1-42.

10. Bhattarai S, K C S, Lama S, Rijal S. Hepatitis B vaccination status and needle-stick and sharps-related injuries among medical school students in Nepal: a cross-sectional study. BMC Res Notes. 2014; 7:774.

https://doi.org/10.1186/1756-0500-7-774

11. Khan N, SM, Siddiqui SH, Merchant AA. Effect of gender and age on the knowledge, attitude and practice regarding hepatitis $\mathrm{B}$ and $\mathrm{C}$ and vaccination status of hepatitis B among medical students of Karachi, Pakistan. J Pak Med Assoc.2010; 60:450-45.

12. Noubiap JJN, Ndoula ST, Agyingi LA. Occupational exposure to 
blood, hepatitis B vaccine knowledge and uptake among medical students in Cameroon. BMC Med Edu.2013;13:148.

https://doi.org/10.1186/1472-6920-13-148

13. Holmberg SD, Suryaprasad A, Ward JW. Updated CDC recommendations for the management of hepatitis B virus-infected health-care providers and students. US Department of Health and Human Services, Centers for Disease Control and Prevention. 2012, 20;61:1-12.

14. Tanaka F. ICP Text of ICP for an infection control practitioner. Osaka: medicus Shuppan; 2006; page. 152-8.

15. Solanky P, Baria H, Nerulkar A, Chavda N. Knowledge and practice of universal precautions among nursing staff at a tertiary care hospital in South Gujarat, India. Int J Community Med Public Health. 2016;3:2373-76.

https://doi.org/10.18203/2394-6040.ijcmph20162890

16. Haridi HK, Al-Ammar AS, Al-Mansour MI. Compliance with infection control standard precautions guidelines: a survey among dental healthcare workers in Hail Region, Saudi Arabia. J Infect Prev. 2016;17:268-76.

https://doi.org/10.1177/1757177416645344

17. Taha F, Janakiram C, Joseph J, Dental Infection control Practices and Public perception: A Crossectional Study. J Inter Oral Health, 2015;7:20-6

18. Roy R, Karim M, Bhattacharjee B. Hepatitis B virus infection and vaccination status among health care workers of a tertiary care hospital in Bangladesh. J Sci Soc. 2015;42:176-79.

https://doi.org/10.4103/0974-5009.165561
19. Nagao Y, Matsuoka H, Sata M. HBV and HCV infection in Japanese dental care workers. Int J Mol Med. 2008;21:791-99.

https://doi.org/10.3892/ijmm.21.6.791

20. Azodo C.C • Ehigiator O, Ojo M.A. Occupational Risks and Hepatitis B Vaccination Status of Dental Auxiliaries in Nigeria. Med Princ Pract. 2010;19:364-66.

https://doi.org/10.1159/000316374

21. Adenlewo OJ, Adeosun PO, Fatusi OA. Medical and dental students' attitude and practice of prevention strategies against hepatitis B virus infection in a Nigerian university. Pan Afr Med J.2017;9:28:33.1-8. https://doi.org/10.11604/pamj.2017.28.33.11662

22. Ibrahim N, Idris A. Hepatitis B Awareness among Medical Students and TheirVaccination Status at Syrian Private University. Hept Res and Treat. 2014; Article ID 131920.1-7

https://doi.org/10.1155/2014/131920

23. Simard EP, Miller JT, George PA, Wasley A, Alter MJ, Bell BP et al. Hepatitis B Vaccination Coverage Levels Among Healthcare Workers in the United States. Infect Control Hosp Epidemiol. 2007; 28: 783-90.

https://doi.org/10.1086/518730

24. Singh SP, Swain M, Kar IB. HBV and Indian medical and dental students.Hep B Annual.2004;1:229-39

25. Habiba S, Alrashidi G, Al-Otaibi A, Makboul G, El-Shazly MK. Knowledge, attitude and behavior of health care workers regarding hepatitis B infection in primary health care, Kuwait. Greener Journal of Medical Sciences. 2012;2:77-83.

https://doi.org/10.15580/GJMS.2012.4.GJMS1221 